\title{
Barriers to Health Service Access: A Study on Conditioning Factors of Self-Health and Illness Perception in Argentina
}

\author{
Gustavo H. Marin, Pablo Vetere, Lupe Marin, Lucia Giangreco, Santiago Dalto, Gladys Garcia, \\ Juan Alconada-Magliano, Gina Marin, Ma. Laura Ferrero, Marcelo Bourgeois, \\ Ma. Gabriela Madonia, Virginia Moran, Aylen Jauregui, Aldo Madeo, Silvina Gygli, \\ Laura Soibelzon, Cloe Marin, Patricia Rivadulla, Maria Raffaeli, Daniela Sbattella, Jorge Agueda, \\ Griselda Haag, Graciela Etchegoyen, Ricardo Wright, Horacio Pracilio, Adriana Arinavarreta \\ Catedra de Salud y Medicina Comunitaria, Facultad de Ciencias Médicas, Universidad Nacional de La Plata, La Plata, Argentina \\ Email: gmarin@med.unlp.edu.ar
}

How to cite this paper: Marin, G. H., Vetere, P., Marin, L., Giangreco, L., Dalto, S., Garcia, G., Alconada-Magliano, J., Marin, G., Ferrero, Ma. L., Bourgeois, M., Madonia, Ma. G., Moran, V., Jauregui, A., Madeo, A., Gygli, S., Soibelzon, L., Marin, C., Rivadulla, P., Raffaeli, M., Sbattella, D., Agueda, J., Haag, G., Etchegoyen, G., Wright, R., Pracilio, H., \& Arinavarreta, A. (2021). Barriers to Health Service Access: A Study on Conditioning Factors of Self-Health and Illness Perception in Argentina. Advances in Applied Sociology, 11, 315-334. https://doi.org/10.4236/aasoci.2021.116029

Received: June 3, 2021

Accepted: June 27, 2021

Published: June 30, 2021

Copyright $\odot 2021$ by author(s) and Scientific Research Publishing Inc. This work is licensed under the Creative Commons Attribution International License (CC BY 4.0).

http://creativecommons.org/licenses/by/4.0/

\begin{abstract}
Aims: To determine self-health image and illness perception as potential barriers to health services access among inhabitants of La Plata, Buenos Aires, Argentina. Methods: A cross-sectional study, where survey, "Brief IllnessPerception Questionnaire" and basic medical examination were performed on 2430 participants at homes. Results: Although men showed a better concept of their state of health, they perceived their illness worse and belatedly. Only $45 \%$ of participants perceived symptoms disease, and from them, $48 \%$ finally decided to consult to the health system. Hence, from every 100 sick people, only 21 had access to a health institution. Higher level of education achieved, better socio-economic conditions or holding health insurance were significantly associated with appropriate health seeking, and access to health service. Conclusions: Self-health image and disease perception affected people's access to health services. Participants of this study showed suboptimal disease perception, manifested as meager and delayed demand for care. These results demonstrate the weakness of current health care model based on people's spontaneous demand. It is necessary to adopt a new health system for the entire population, regardless of the self-awareness that people may have about their own health/disease status. It would be a more inclusive, effective and efficient healthcare model.
\end{abstract}

\section{Keywords}

Demand-Side Barriers, Illness Perception, Self-Health Image, Health Care Model 


\section{Introduction}

Perception enables a cognitive process that allows us, through our senses, to build representations about aspects that we experience.

The perception of the state of health in people and the awareness of their diseases can be influenced by many circumstances, since a "disease" is in turn a very personal ailment and a cultural construction. Thus, each subject experiences build a specific behavior in the presence of signs or symptoms that allow them to identify the presence of anomalies. Hence, perceiving oneself as "healthy" has to do with a large number of factors such as social environment, cultural and socioeconomic conditions, the personality, the degree of social support received, and the physiological state of the person. Even today, it is common for most people to define "health" as the absence of disease; standing that individuals only perceive themselves "healthy" when illness is absent (Vega-Franco, 2002). These concepts date back to ancient Greece, in which it was considered a lack of health, the reduction of physical or mental capacities (Sigerist, 1996). Thus, for all cultures, health is understood as "well-being". This phoneme summarizes the complex perception of those people who enjoy a comfortable life, with their basic needs satisfied and in good physical condition, expressing the concept of what "being healthy" implies. With this connotation, a group of experts from the World Health Organization (WHO) defined "health" more than 50 years ago as: "the complete state of physical, mental and social well-being and not just the absence of disease or disability." It cannot be denied that in this explanation, the elements of the discourse that translate "health" are transferred to the concept of "well-being". However, from the way this definition is stated, it seems that "health" is comparable to a pleasant life physically, mentally and socially, as if the pleasure emanating from the bodily senses was the ultimate goal pursued by a healthy earthly life. However, being in permanent full physical and mental well-being is practically impossible for anyone that is why this definition is associated with a "medicalizing" view of health. Other authors, such as Floreal Ferrara (Ferrara, 1993), have defined health "as the ability to face and overcome the conflicts and adversities that the environment presents us". In reference to this last concept, we know that inequalities in the level of opportunities generated in living conditions give rise to unfair differences that deepen over time. Hence, the impact of the socio-economic crisis turns unemployment and low income into long-term phenomena, which extend from material aspects to other social dimensions that finally translates into health problems (Ferrara, 1993). Public policies, advances in medicine, and health technology seek to reduce the morbidity and mortality associated with the different diseases that afflict humanity. However, the systems are organized from the centrality of health institutions that provides health care to those members of the Community that demand attention (Marin, 2019).

Demanding health care unfortunately is not always linked to the control and care of people health, but it does to the concept of "reparation/restitution" for when health status is lost. In other words, demanding for care is linked to the 
concept of illness rather than health, and it depends on the feelings that the population has about their health status, which will determine the types of help to seek. There is a complex world of beliefs and values, norms, knowledge and behaviors explicitly linked to health/disease concepts that permanently interact with formal medicine and that account not only for the modalities of health management, but also for the relationship that people have with its body, the food that eats, lifestyle habits, free time activities, and health services (Kornblit \& Mendes Diz, 2000).

The use of the health system is then the result of a process that begins with the perception of a health problem whose solution is perceived as necessity, and is later translated into a demand for some type of care. When this demand is later satisfied by the health system, formal or not, it is considered that there is a real utilization of these services. Each Society and each family group resolves day by day how it should take care of the health of its members and how should be done to recover it when it health is deteriorated (Gómez Lopez, 2000). There are situations where it is difficult to distinguish between the condition due to the illness perceived by the people, and the illness as a recognized state classified by the intervention of a health professional (objective condition). This dual perspective of the idea of "disease" allows to understand more clearly the reason for the behavior of people in situations of illness, since in some cases an ailment considered banal or less important by a health professional might trigger a consultation to the health system; on the other hand, a serious disease may not cause a promptly demand for help.

In other words, there are different ways of perceiving a health problem, since it exist a diversity of meanings that are attributed to the fact of being "healthy" or "sick". Perceiving is then conditioned by health determinants (such as age, sex and material living conditions, responsibility or the family role that the person plays, the daily priorities and the activities developed) and health determinations (historical, social, politics, and economical baggage of the Community where people belongs) (Llovet, 1984). All these conditions influence the decision to demand care from the formal health system.

Before people claim for care in the health service, they have most likely carried out some type of action, which responds to a "self-care" concept (Menéndez, 2004). Health personnel do not always take patient's path background before they demand to a health service, which is a great mistake since the "look" of patient's about his own problem, is an important data to be considered. Despite the relevance that has for the patients, a diagnosis and a proper treatment to take care of their ailment; it should be considered patients' own conception and representation of what may be happening to them, in order to get better results in health care process.

Whatever the situation could be, the classic of health care system organization always needs the will of individuals to demand for care. Nonetheless, this reveals a disadvantage of the system: the demand for care requires a previous step, which is this perception of the needs or the loss of "health" status, which, as mentioned, 
is very unequal among the members of a Society and depends on many factors. This healthcare seeking behavior (HSB) has been defined as, "any action or inaction undertaken by individuals who perceive themselves to have a health problem or to be ill for the purpose of finding an appropriate remedy" by Mac Kian (MacKian, 2003).

For this reason, determining these factors, as well as studying the ways in which populations perceive their health status, detect its loss, and decide to consult the health system for a potential disease care, are vital topics that must be taking into account by health systems. In order to deepen our knowledge of these aspects, we developed this study.

\section{Methodology}

\subsection{Study Design}

This is a descriptive cross-sectional study, conducted between March 2018 to November 2019 at Gran La Plata Area (Capital Region of Buenos Aires State), Argentina.

\subsection{Participants \& Procedures}

Participants were voluntarily recruited in a door to door visit. The districts included in the study were subdivided into neighborhoods and in census fractions. Each area was mapped and each home was identified by Google Maps Platform Software (https://www.google.es/maps). 684 advanced medical students and 32 teachers participated in the study. Students received special training in communication to conduct interviews, and participated in various meetings to become familiar with the guidelines for the operational definitions of the survey. Groups of 2 students were assigned to each home in order to perform the survey. Twice the students visited each household, in order to establish the willingness of its members to participate in the study, to perform the survey and a basic medical exam. One university teacher for every 5 groups of students monitored the appropriate development of the household surveys, to verify compliance with the defined operational guidelines.

The inclusion criteria were: 1) to be over 18 years of age and 2) to understand either the issues rose to give the informed consent or the items from the questionnaire, 3) a maximum of 2 of two adults surveyed for each household. The only exclusion criterion was cognitive and psycho-physiological impairment. For each participant, students made a brief presentation were they provided simple description of the study and its procedures, and an assurance of confidentiality. The questionnaires were administered in quiet settings, in quiet place. One of the students asked the survey questions while the other registered the responses. After a control of the survey done, a second visit to the home was performed by the teacher and the same students, in order to check any question for which there were doubts and to finish a basic medical exam: weight and height measurement, blood pressure control, and glycaemia (test strips with automatic reader 
Accu-chek).

In case of abnormality detection of any of these parameters, individuals were asked to attend an appointment at the nearest Public Health Center to rule out a diagnosis of chronic disease). All subjects gave their informed consent to participate in the study. The study protocol was approved by the Ethical Committee of CIC-PBA.

\subsection{Sample Size}

The sample size was calculated using a $G^{*}$ power version 3.1 program for linear multiple regression analysis; performing a pilot study with 180 participants measuring variables include in the study (a type I error of 0.05 , a power of 0.95 , and an effect size of 0.15 were considered). According to this preliminary results, we a total of 3000 participants were expected to be enrolled, considering a 15\% dropout rate and the socio-economic conditions of the geographical areas were homes were located (extracted from INDEC National Statistical and Census Institute). .

\subsection{Variables}

The variables considered in this study were Gender (SEX); Marital status (MASTAT); Living arrangements (LA), Socioeconomic structural conditionsbasic need unsatisfied (BNU); Income Level-Financial situation now (FISIT); Highest Educational Level Achieved (HELA); Employment status (ESTAT); Insurance Status (IS); Perceived health status (PHS), Disease Perception (DP), Cognitive components of health/illness perception (CCHIP); Healthcare seeking behavior (HCB) facing a symptom or a health problem. Distance to Health Institution (DHI): distance from responder's home to a health care center.

Operational Definitions of Variables. For Gender (SEX): either female or male; Marital status (MASTAT); Marital status (MASTAT): Married/in couple, Single, Separated/Divorced; Living arrangements (LA): means with whom the responder lives. Options only with couple, alone (solitary), with children or relatives; Socioeconomic structural conditions-basic need unsatisfied (BNU) expressed by one of these 5 concepts: Precarious housing; Sanitary deficiencies (households that do not have a toilet); Overcrowding Conditions (more than 3 inhabitants per room); School non-attendance (households that have at least one school-age child (6 to 12 years old) who does not attend school; Subsistence capacity (includes households that have four or more people per employed member and that have a head who does not has completed the third grade of primary schooling); Income level or Financial situation now (FISIT): to determine this variable, was established whether the family income of the household reaches the total cost of all essential resources (basic basket of edible inputs and clothing); Highest Educational Level Achieved (HELA): This item establishes the maximum educational level reached by the respondent, and is classified into 3 categories Basic Education, High School and University-Tertiary; Employment status (ESTAT): ca- 
tegorized by employed or unemployed status; Insurance Status (IS): means if responder has Health Coverage at the time of survey performance; Distance to Health Institution (DHI): means the average distance from the home of the respondents to a health center (measured in kilometers); Cognitive components of health/illness perception (CCHIP): Cognitive components of health/Illness perception were explored around five themes: Identity-which is comprised of the label of the illness and the symptoms the patient views as being part of the disease (i.e.: nausea, sore, dizziness, sore joints, fatigue, muscle pain); Cause-personal ideas about etiology which may include simple single causes or more complex multiple causal models (i.e.: virus, bacteria, pollution of the environment; stress); Time-line-how long the patient believes the illness will last. (i.e.: acute, chronic or episodic; or temporary, permanent); Consequences-expected effects and outcome of the illness (i.e.: harmless, major, serious); and Cure/controlhow one recovers from, or controls, the illness (i.e.: like can be done, treatment is highly effective); Perceived health status (PHS): categorized by 6 levels on how the respondent rates their own health: very bad, bad, fair, good, very good, excellent, Disease Perception (DP): this item measures the degree if the respondent perceives a symptom or manifest disease and the cattery is dichotomous (Yes or No); Healthcare seeking behavior (HSB): was classified as appropriate or inappropriate, status that was defined by the student first and afterward by the teacher (which is a medical doctor) that monitored each of the groups made up of the two medical students responsible for the interview in each household. Appropriated HSB was defined by consulting a qualified medical professional or seeking healthcare at orthodox health facilities such as primary health centers general public hospitals or private health institutions; during illness episodes or any situation requiring medical attention. Inappropriate HSB comprises seeking healthcare from consultation to friend, neighbors, family members or doing nothing at all when signs or symptoms were perceived.

The presence or absence of prevalent disease like blood hypertension, diabetes, health diseases and other illness were detected either by additional questions added to the survey or by the basic examination performed during the home's visit.

\subsection{Instrument for Data Collection}

Data was collected concerning perceived health status and health-related characteristics such as symptoms, signs, illnesses; and how respondents perceived these characteristics.

Health Status/Illness perception was measured using the Illness Perception Questionnaire (IPQ) adapted by researchers of the present study to local population and needs from Leventhal (Leventhal, 1997; Leventhal, 2001). Perceived health status was assessed using a 3-item questionnaire with possible scores ranging from 1 (very bad) to 5 (very good). The higher the average score of the 3 items, the better the perceived health status. The list of domains assessed by this 
instrument includes components related to coherence, concern, consequences, control (personal and treatment), emotional representation, identity, and timeline (acute/chronic and cyclical) with were represented by the variables selected for this study.

The components provide a framework for patients to make sense of their symptoms, assess health risk, and act accordingly. Each of these components holds a perception about one aspect of the illness and together they provide the individual's coherent view of an illness (Leventhal, 1997, 2001).

The major cognitive components included were: Identity-which is comprised of the label of the illness and the symptoms the patient views as being part of the disease; Cause-personal ideas about etiology which may include simple single causes or more complex multiple causal models; Time-line-how long the patient believes the illness will last. These were categorized into acute, chronic or episodic; Consequences-expected effects and outcome of the illness; and Cure/ control-how one recovers from, or controls, the illness, in scores adapted from IPQ available versions like Broadbent (Broadbent et al., 2006); Moss-Morris (Moss-Morris, 2002) and Weinman (Weinman et al., 1996).

A number of additional questions were included in order to detect ten particular groups of illness related to cardiovascular diseases, type 2 diabetes, renal disease, asthma, osteoarticular disease, mental health diseases, endocrine pathologies, infectious diseases, gastrointestinal diseases, or minor illnesses (allergies, colds, headaches). A basic health examination was performed in each case.

\subsection{Literature Reviewing Process}

Regarding conditioning factors of self-health and illness perception, it was performed a literature review. The keyword search was elaborated by the first results for increasing accuracy in the search. Combinations of following keywords were used: "health perception", "disease", "illness", "cognitive", "healthcare seeking behavior". The search was conducted on academic databases which have large repository of academic studies and high popularity in web based academic researches. In this context, SCOPUS.COM, SCIENCEDIRECT.COM PubMED, MEDLINE Pro, MEDSCAPE, MEDLINE plus, MDX Health, CINAHL, ERIC, and JSTOR databases. We limited the searches to articles in English and those with abstracts. Searches returning more than 300 articles were further filtered by using terms such as "questionnaire", "health" and "perception". We undertook 23 searches from all databases that were considered with highly importance for the research.

\subsection{Statistical Analyses}

All data analysis was conducted using SPSS version 24. Descriptive statistics were used to define the general characteristics and variables (Table 1). Linearity was verified through scatterplot before performing Pearson's correlation analysis and multiple regression analysis. Pearson's correlation analysis was performed 
Table 1. Description of variables.

\begin{tabular}{|c|c|c|}
\hline Variable & Operational Definition & $\begin{array}{l}\text { Instrument of } \\
\text { Data Collection }\end{array}$ \\
\hline Gender (SEX) & Male/Female & General Survey \\
\hline $\begin{array}{l}\text { Marital Status } \\
\text { (MASTAT) }\end{array}$ & $\begin{array}{c}\text { Married/in couple, } \\
\text { Single, Separated/Divorced }\end{array}$ & General Survey \\
\hline $\begin{array}{l}\text { Living arrangements } \\
\text { (LA) }\end{array}$ & $\begin{array}{l}\text { with couple, alone (solitary), } \\
\text { with children or relatives }\end{array}$ & General Survey \\
\hline $\begin{array}{l}\text { Socioeconomic structural } \\
\text { conditions -basic need } \\
\text { unsatisfied (BNU) }\end{array}$ & $\begin{array}{l}5 \text { concepts: home services, } \\
\text { overcrowding, school attendance, } \\
\text { unemployment, education }\end{array}$ & General Survey \\
\hline $\begin{array}{l}\text { Income Level-Financial } \\
\text { situation now (FISIT) }\end{array}$ & $\begin{array}{l}\text { Family income able to reach the } \\
\text { total cost of all essential resources }\end{array}$ & General Survey \\
\hline $\begin{array}{c}\text { Highest Educational } \\
\text { Level Achieved (HELA) }\end{array}$ & $\begin{array}{l}\text { Basic Education, High School } \\
\text { and University-Tertiary }\end{array}$ & General Survey \\
\hline $\begin{array}{l}\text { Employment status } \\
\text { (ESTAT) }\end{array}$ & Employed or unemployed & General Survey \\
\hline $\begin{array}{c}\text { Insurance Status } \\
\text { (IS) }\end{array}$ & Presence of Health Coverage & General Survey \\
\hline $\begin{array}{l}\text { Distance to Health } \\
\text { Institution (DHI) }\end{array}$ & $\begin{array}{l}\text { distance from homes to a } \\
\text { health care center }(\mathrm{km})\end{array}$ & General Survey \\
\hline $\begin{array}{l}\text { Perceived health } \\
\text { status (PHS) }\end{array}$ & $\begin{array}{l}\text { very bad, bad, fair, good, } \\
\text { very good, excellent }\end{array}$ & $\begin{array}{c}\text { Illness Perception } \\
\text { Questionnaire (IPQ) }\end{array}$ \\
\hline $\begin{array}{l}\text { Disease Perception } \\
\text { (DP) }\end{array}$ & Yes or No & $\begin{array}{c}\text { Illness Perception } \\
\text { Questionnaire (IPQ) }\end{array}$ \\
\hline $\begin{array}{l}\text { Cognitive components of } \\
\text { illness perception (CCHIP) }\end{array}$ & $\begin{array}{l}\text { Identity, cause, time-line, } \\
\text { consequences, cure/control }\end{array}$ & $\begin{array}{c}\text { Illness Perception } \\
\text { Questionnaire (IPQ) }\end{array}$ \\
\hline $\begin{array}{l}\text { Healthcare seeking } \\
\text { behavior }(\mathrm{HCB})\end{array}$ & Appropriate or inappropriate & $\begin{array}{c}\text { Illness Perception } \\
\text { Questionnaire (IPQ) }\end{array}$ \\
\hline Disease detected & CIE-10 disease description & $\begin{array}{c}\text { IPQ and basic } \\
\text { health examination }\end{array}$ \\
\hline
\end{tabular}

for perceived health status, occupational stress, sleep quality, and motives for food choices. Step-wise multiple regression analyses were used to examine factors influencing perceived health status. The multivariate linear regression was adjusted for general characteristics such as age, gender, level of education, living arrangements, and the number of illnesses. Statistical significance was set at a $p$-value of $<0.05$.

\section{Results}

\subsection{General Data}

From the 2464 participants who completed the survey, 2430 were included in the data analysis, as 34 were excluded due to incomplete responses. Of them, 59.3\% $(n=1441)$ were female and $40.7 \%(n=989)$ male. The mean age was $54.7 \pm 23.4$ years and the median was 54 years. Marital status, living arrangements and edu- 
cational level achieved are shown in Table 2. Sixty-six percent of responders reported having employment at the time of the survey performance (Table 3). $36.4 \%$ of those surveyed, have salaries below the poverty line since their incomes

Table 2. Characteristics of the participants.

\begin{tabular}{cc}
\hline Characteristics & Mean \pm SD or Number (\%) \\
\hline Age, years, mean (SD) & $54.7 \pm 23.4$ \\
$\leq 29$ & $312(12.84)$ \\
$30-49$ & $910(37.44)$ \\
$50-64$ & $749(30.82)$ \\
$\geq 65$ & $459(18.88)$ \\
\hline
\end{tabular}

$\begin{array}{cc}\text { Gender } & \\ \text { Female, n (\%) } & 1441(59.3) \\ \text { Male n (\%) } & 989(40.7)\end{array}$

\begin{tabular}{cc} 
Marital Status & $989(40.7)$ \\
Married or in couple & $1401(57.7)$ \\
Single & $315(13.0)$ \\
Separated/Divorced & $511(21.0)$ \\
Widowed & $203(8.3)$ \\
\hline
\end{tabular}

\section{Living arrangements $\mathbf{n}(\%)$}

With couple

Solitary

$314(12.9)$

With children/relatives

$1629(67.0)$

\section{Higher Level of education obtained}

Elementary school

$604(24.8)$

High school

$1437(59.1)$

University/Tertiary

$389(16.0)$

Income (economic) level, $\mathrm{n}(\%)$

Upper

$199(8.2)$

Middle

$1346(55.4)$

Lower

$885(36.4)$

Social condition (structural) BNU n (\%)

BNU yes

$882(36.3)$

BNU no

$1548(63.7)$

Employment status, n (\%)

Employed

$1606(66.1)$

Unemployed

Retired

$245(10.0)$

\section{Insurance Status}

Insured 
Table 3. Perceived Health Status (PHS) and Disease Perception (DP) according to variables considered in the study.

\begin{tabular}{|c|c|c|c|c|}
\hline \multirow[b]{2}{*}{ Variables } & \multicolumn{2}{|c|}{ PHS $^{*}$} & \multicolumn{2}{|c|}{$\mathrm{DP}^{* *}$} \\
\hline & $\begin{array}{l}\text { E-VG-G } \\
\text { (n 1747) }\end{array}$ & $\begin{array}{l}\text { F-B-VB } \\
\text { (n 683) }\end{array}$ & $\begin{array}{c}\text { Yes } \\
(\mathrm{n} \mathrm{414)}\end{array}$ & $\begin{array}{c}\text { No } \\
\text { (n 507) }\end{array}$ \\
\hline \multicolumn{5}{|c|}{ Age (years) } \\
\hline$\leq 29$ & $256(82.0 \%)$ & $56(18.0 \%)$ & $59(43.4 \%)$ & $77(56.6 \%)$ \\
\hline $30-49$ & $655(72.0 \%)$ & $255(28.0 \%)$ & $155(44.4 \%)$ & $194(55.6 \%)$ \\
\hline $50-64$ & $511(68.2 \%)$ & $238(31.8 \%)$ & $118(45.6 \%)$ & $140(54.4 \%)$ \\
\hline$\geq 65$ & $299(65.2 \%)$ & $72(23.0 \%)$ & $82(46.1 \%)$ & $96(53.9 \%)$ \\
\hline \multicolumn{5}{|c|}{ Gender } \\
\hline Female & $963(66.8 \%)$ & $478(33.2 \%)$ & $244(44.7 \%)$ & $302(55.3 \%)$ \\
\hline Male & $737(74.5 \%)$ & $252(25.5 \%)$ & $113(30.2 \%)$ & $262(69.8 \%)$ \\
\hline \multicolumn{5}{|c|}{ Marital Status } \\
\hline Married or in couple & $1026(73.2 \%)$ & $375(26.8 \%)$ & $241(44.3 \%)$ & $313(55.6 \%)$ \\
\hline Single & $222(70.5 \%)$ & $93(29.5 \%)$ & $54(43.5 \%)$ & $70(56.5 \%)$ \\
\hline Separated/Divorced & $368(72.1 \%)$ & $143(27.9 \%)$ & $96(46.7 \%)$ & $109(53.3 \%)$ \\
\hline Widowed & $145(71.5 \%)$ & $58(28.5 \%)$ & $22(45.2 \%)$ & $26(54.8 \%)$ \\
\hline \multicolumn{5}{|c|}{ Living arrangements n (\%) } \\
\hline With couple & $354(72.7 \%)$ & $133(27.3 \%)$ & $88(45.3 \%)$ & $106(54.7 \%)$ \\
\hline Solitary & $222(70.8 \%)$ & $92(29.2)$ & $42(44.7 \%)$ & $52(55.3 \%)$ \\
\hline With children/relatives & $1176(72.2 \%)$ & $453(27.8)$ & $285(45.0 \%)$ & $348(55.0 \%)$ \\
\hline
\end{tabular}

Higher Level of education achieved

\begin{tabular}{|c|c|c|c|c|}
\hline Elementary school or lower & $440(72.9 \%)$ & $164(27.1 \%)$ & $107(43.5 \%)$ & $140(56.5 \%)$ \\
\hline High school & $1030(71.7 \%)$ & $407(28.3 \%)$ & $243(45.1 \%)$ & $295(54.9 \%)$ \\
\hline University/Tertiary & $276(70.9 \%)$ & $114(29.1 \%)$ & $63(46.2 \%)$ & $73(53.8 \%)$ \\
\hline \multicolumn{5}{|c|}{ Income (economic status) level } \\
\hline Upper & $146(73.3 \%)$ & $53(26.7 \%)$ & $33(46.9 \%)$ & $38(53.1 \%)$ \\
\hline Middle & $962(71.5 \%)$ & $384(28.5 \%)$ & $202(44.2 \%)$ & $254(55.8 \%)$ \\
\hline Lower & $626(70.8 \%)$ & $259(29.2 \%)$ & $171(43.5 \%)$ & $223(56.5 \%)$ \\
\hline \multicolumn{5}{|c|}{ Social condition (structural) BNU } \\
\hline BNU yes & $637(72.2 \%)$ & $245(27.8 \%)$ & $110(31.9 \%)$ & $234(68.1 \%)$ \\
\hline BNU no & $1108(71.6 \%)$ & $440(28.4 \%)$ & $253(43.9 \%)$ & $324(56.1 \%)$ \\
\hline \multicolumn{5}{|c|}{ Employment status } \\
\hline Employed & $1137(70.8 \%)$ & $469(29.2 \%)$ & $282(45.8 \%)$ & $333(54.2 \%)$ \\
\hline Unemployed & $408(70.5 \%)$ & $171(29.5 \%)$ & $102(44.2 \%)$ & $128(55.8 \%)$ \\
\hline Retired & $182(74.4 \%)$ & $63(25.6 \%)$ & $34(44.8 \%)$ & $42(55.2 \%)$ \\
\hline \multicolumn{5}{|c|}{ Insurance Status } \\
\hline Insured & $891(72.3 \%)$ & $341(27.7 \%)$ & $207(45.6 \%)$ & 247 (54.4\%) \\
\hline Uninsured & $858(71.6 \%)$ & $340(28.4 \%)$ & $206(44.2 \%)$ & $261(55.8 \%)$ \\
\hline
\end{tabular}




\begin{tabular}{lllll}
\hline \multicolumn{5}{c}{ Distance to Health Institution } \\
$<2 \mathrm{~km}$ & $745(71.7 \%)$ & $295(28.3 \%)$ & $187(45.3 \%)$ & $226(54.7 \%)$ \\
$>2 \mathrm{~km}$ & $1005(72.3 \%)$ & $385(26.7 \%)$ & $227(44.7 \%)$ & $281(55.3 \%)$ \\
\hline
\end{tabular}

PHS: Perceived health status—categorized by 6 levels on how the respondent rates their own health: (VB) very bad, (B) bad, (F) fair, (G) good, (VG) very good, (E) excellent. DP: Disease Perception-measures whether if respondents perceived a symptom or disease * Data extracted from 2430 participants. ${ }^{* *}$ Data extracted from 921 participants that had a health problem during the last 15 days.

did not achieve the basic basket (food and clothing) and in $11.6 \%$ of the cases indigence was detected since monthly home salaries were under basic food basket (Table 2). About unsatisfied basic needs, it could be said that $36.5 \%$ of the people included in the study had structural poverty (Table 3 ). The average distance from the home of the respondents to a health center was $1.12 \pm 2.9 \mathrm{~km}$.

\subsection{Habits}

Regarding the habits of the respondents, it was detected that $27.6 \%$ of them smoked at least 3 cigarettes per day, with an average of $10.3 \pm 9.5$ cigarettes/day. Regarding alcohol consumption, $21.3 \%$ of the subject included in the study ingested at least 20 grams of alcohol daily or 140 grams weekly.

In relation to weight, it was found that at the time visiting the home, $16.5 \% \pm$ $0.39 \%$ of the respondents were overweight, $35.1 \% \pm 0.49 \%$ were overweight and $48.4 \% \pm 0.57 \%$ had normal weight.

Of all households visited, $21.8 \%$ of them had a device for recording blood pressure (BP); while $44.7 \%$ of the families had own thermometers to record their body temperature, and have the habit to regularly test their BP.

\subsection{Perception of Health}

Regarding the judgment of the health status of participants enrolled in the study, $3.5 \%$ of them stated that their health status was excellent, $18.8 \%$ very good, $49.6 \%$ good, $17.1 \%$ fair, $8.6 \%$ bad and $2.4 \%$ considered "very bad" their own health. The only variable that was statistically significant in relation to the perception of health status was gender, since males considered that their health was excellent, good or very good in $74.51 \%$ while the females this perception was lower $66.8 \%, p=0.003$.

In relation about health problem or disease perception, $37.9 \%(n=921)$ of all surveyed had a health problem within the last 15 days or that the problem was detected at the time of the home visit (Table 3). From them, only 414 subjects (44.9\%) perceived that they had had a health problem, while the rest $(n=506$ $55.1 \%$ ) did not spontaneously perceived signs or symptoms until they were specifically asked about them or were detected at the medical examination (Table 3).

Noteworthy, only 198 people from those that did perceive a health problem consulted to a professional of the health system. The place chosen for that atten- 
tion was a public hospital $(24.2 \%)$, a primary care center $(18.2 \%)$, a privet doctor's cabinet (10.7\%), a private institution (37.9\%), at home (3.6\%), at work (3.1\%), others $(2.3 \%)$. Among those who consulted, the problem was considered solved in $74.2 \%$. Insured respondents $(87.6 \%)$ preferred the private healthcare sector while among not insured population $46.6 \%$ also chose to be attending in private institutions.

Among those participants that had a health problem but did not consult to the health system, the main reasons given were lack of time (14.2\%), lack of money (3.1\%), because they self-medicated (26.2\%), to avoid losing hours of their jobs (10.2\%), to avoid leaving the children alone $(23.1 \%)$, because they did not consider it important $(12.9 \%)$ or because the administrative procedures are complex $(10.3 \%)$.

Concerning the cause of the health problem detected, from all 921 responders, $40.2 \%$ had colds or flu problems, $19.4 \%$ pain or osteoarticular problems, $11.3 \%$ gastrointestinal problems, $9.7 \%$ headache, $8.5 \%$ dizziness or vertigo, while $10.9 \%$ had other health problems.

The participants' health seeking behavior was associated with several factor but educational level and socio-economic status were the only variables that demonstrated a statistically significant difference (Table 4).

The only variables with statistical relation to health problem/disease perception were gender (females $44.7 \%$ vs males $30.2 \% p=0.02$ ) and socioeconomically structural conditions (31.9\% of people with BNU vs $43.9 \%$ of the non BNU perceived disease/health problems, $p=0.01$ ).

\subsection{Health Status \& Health System}

The blood pressure controls performed, detected blood hypertension in 39.6\% of the cases (hypertension was confirmed by health system in further consultation in $36.9 \%$ of the cases, $4.1 \%$ of them did not know than they have a previous blood pressure problem). Elevated blood glucose values were detected in $19.3 \%$ ( $n=360$ ) of the 1864 individuals who agreed to take the ambulatory glucose test; although only $12.4 \%$ confirmed diabetes with a glucose tolerance test performed in subsequent medical consultations.

Regarding oral health, it was determined that only $3.6 \%$ attended the dentist in the last year, the most common cause (78.4\%) was an emergency situation (pain or loss of a tooth). $4.9 \%$ of the participants never attended the dental consultation, while only $20.5 \%$ of the respondents stated that they regularly consult the dentist. $43.7 \%$ of these consultations were made in the last 6 months, $16 \%$ less than 1 year, $26.2 \%$ between 1 and 5 years, $12.8 \%$ more than 5 years ago, while $3.7 \%$ do not remember dates.

About the place in which the participants received the last health care for their illness was $20.2 \%$ in a public hospital; $11.6 \%$ in a Primary Health Care Center; $49.7 \%$ in a private hospital, $17.1 \%$ health office, $1.1 \%$ at work and 0.3 at home.

The opinion of the institution and the medical care service received by people 
Table 4. Factors associated with healthcare seeking behavior of respondents perceived illness within the last 15 days.

\begin{tabular}{|c|c|c|c|c|c|c|}
\hline \multirow{3}{*}{ Characteristics } & \multicolumn{2}{|c|}{ Innappropiated HSB } & \multicolumn{2}{|c|}{ Appropiated HSB } & \multirow{3}{*}{$X^{2}$} & \multirow{3}{*}{$p$-value } \\
\hline & $\mathbf{N}$ & $\%$ & $\mathbf{N}$ & $\%$ & & \\
\hline & 723 & 78.5 & 198 & 21.5 & & \\
\hline \multicolumn{5}{|c|}{ Gender } & 0.05 & 0.93 \\
\hline Female & 541 & 74.8 & 148 & 74.7 & & \\
\hline Male & 182 & 25.2 & 50 & 25.3 & & \\
\hline \multicolumn{5}{|c|}{ Age Group } & 1.75 & 0.59 \\
\hline$<29$ & 170 & 23.5 & 48 & 24.3 & & \\
\hline $30-49$ & 260 & 35.9 & 72 & 35.9 & & \\
\hline $50-64$ & 204 & 28.2 & 53 & 26.3 & & \\
\hline$>65$ & 89 & 12.3 & 25 & 12.2 & & \\
\hline \multicolumn{5}{|c|}{ Level of Education } & 40.4 & $<0.01$ \\
\hline Elementary school & 306 & 42.4 & 40 & 20.3 & & \\
\hline High school & 349 & 48.2 & 51 & 25.6 & & \\
\hline University/Tertiary & 68 & 9.4 & 107 & 54.1 & & \\
\hline \multicolumn{5}{|c|}{ Marital Status } & 0.38 & 0.54 \\
\hline Married or in couple & 401 & 56.1 & 105 & 52.5 & & \\
\hline Single & 108 & 15.0 & 19 & 9.5 & & \\
\hline Separated/Divorced & 154 & 21.2 & 61 & 30.7 & & \\
\hline Widowed & 55 & 7.7 & 13 & 6.3 & & \\
\hline \multicolumn{5}{|c|}{ Insurance Status } & 73 & $<0.01$ \\
\hline Insured & 220 & 30.4 & 125 & 62.9 & & \\
\hline Uninsured & 503 & 69.6 & 73 & 37.1 & & \\
\hline \multicolumn{5}{|c|}{ Social condition } & 36 & $<0.01$ \\
\hline BNU yes & 436 & 60.3 & 68 & 34.2 & & \\
\hline BNU no & 215 & 29.7 & 119 & 60.1 & & \\
\hline Retired & 72 & 10.0 & 11 & 5.7 & & \\
\hline
\end{tabular}

surveyed was considered excellent (12.7\%), very good (34.7\%), good (41.6\%), fair (7.9\%), bad (2.1\%), very bad (1.5\%), no opinion (3\%).

Among the reasons for choice of health facility/health provider utilized, $42.3 \%$ of respondents considered the good service given by the provider as the most important reason for their patronage of such provider, geographical proximity to their homes was the main reason for $20.4 \%$ of the responders, affordability of services was another reason for $19.4 \%$ of participants, for $11.2 \%$ of responders their choice was based in prompt attention and for $7.1 \%$ of the people a place where exist free available drugs was the main reason at the time to choose the health care institution.

Regarding the health professional who attended study participants, the opi- 
nion was excellent $(22.1 \%)$, very good $(39.7 \%)$, good $(32.8 \%)$, fair $(3.8 \%)$, bad (1\%), very bad $(0.7 \%)$, while $3.3 \%$ did not want to express their opinion. Politeness and courtesy among health workers was considered a major factor in selecting healthcare provider for $27.6 \%$ of participants.

During the last 15 days prior to the first visit of this study 1702 respondents stated that they had consumed medication (1023 female and 679 male). $7.4 \%$ of them consumed 2 or more medications. The therapeutic group to which the drugs used belonged was: antihypertensive (31.1\%), antibiotics (12.7\%), analgesics $(38.7 \%)$, anti-diabetics (15.6\%), antispasmodics (1\%), corticosteroids $(4.2 \%)$, contraceptives $(32.8 \%)$, sedatives $(4.2 \%)$, vitamins $(4.7 \%)$, expectorants $(1 \%)$, others $(28.8 \%)$.

$78.4 \%$ of the patients had to make a partial or total payment for the drugs consumed. The reasons for the consumption of these medications were due to medical prescription (61.8\%), because it gave good results to a similar problem (9.9\%), because it was recommended (12.9\%), because they saw or heard advertising (5.4\%), or for other causes not described (10.0\%). 19.7\% of the participants who had to consume a prescribed medication, could not buy it.

$11.5 \%$ of those surveyed stated that they had been hospitalized during the last year $(29.4 \%$ in a state institution and $70.6 \%$ in a public entity). The average number of days of hospitalization was $6.7 \pm 8.3$ days, the median was 3 days. The main reason for hospitalization was for surgical reasons (33.6\%).

When asked about which is the main source of information about health topics, $32.3 \%$ responded television, $22.3 \%$ social networks, $21.3 \%$ health professional, $9.4 \%$ family members, neighbors or friends, $8.3 \%$ radio; $6.4 \%$ by other sources.

A specific research on the level of consultation of the female population to the gynecologist showed that $1.6 \%$ of them never attended this type of consultation, while $62 \%$ of the respondents admitted attending the gynecologist irregularly. Among the latter, $45.7 \%$ attended their gynecologist in the last six months, $16.1 \%$ in the last year, $24.7 \%$ between 1 to 5 years and $9.1 \%$ consulted more than 5 years ago, while $4.4 \%$ did not remember dates.

When asked if in the last 15 days the respondent performed any of the following practices, the responses were: chemical analysis of blood or urine $(20.7 \%)$, tissue biopsy $(2 \%)$, electrocardiogram $(10.7 \%)$, radiography $(10 \%)$, ultrasound (10\%), tomography (5.3\%), magnetic resonance imaging (3.7\%), endoscopy (1\%), physical therapy $(0.7 \%)$, other (3\%) mammograms/Papanicolau test/densitometry.

$43.5 \%$ of the participants reported having one or more chronic illnesses (mean for number of illness $1.2 \pm 1.14$ ) than was present for more than 3 months (Table 5).

People also stated having a mental health problem, being the most frequent pathology "depression" (363 of the participants), who reported having symptoms or signs of this disease during the last month: loss of interest (58\%), difficulty in perform daily activities (40.7\%), lost work days (17.3\%), weight loss 
Table 5. Diseases or health problems reported.

\begin{tabular}{|c|c|c|}
\hline Disease or health problem & $\mathbf{n}$ & $\%$ \\
\hline High blood pressure & 797 & 32.8 \\
\hline Vascular disease & 85 & 3.5 \\
\hline Heart disorders & 243 & 10.0 \\
\hline Diabetes & 459 & 18.9 \\
\hline Rheumatism & 226 & 9.3 \\
\hline Gastritis & 282 & 11.6 \\
\hline Gallbladder problem & 226 & 9.3 \\
\hline Diarrhea or constipation & 209 & 8.6 \\
\hline Parasites & 34 & 1.4 \\
\hline Hernias & 243 & 10.0 \\
\hline Cancer & 51 & 2.1 \\
\hline Infectious diseases & 85 & 3.5 \\
\hline Blood diseases & 93 & 2.2 \\
\hline Allergy & 736 & 17.4 \\
\hline Asthma & 236 & 9.7 \\
\hline Chewing problems & 313 & 7.4 \\
\hline Sensitive gums & 289 & 11.9 \\
\hline Caries & 690 & 28.4 \\
\hline Anxiety & 396 & 16.3 \\
\hline Insomnia & 503 & 20.7 \\
\hline Anguish & 384 & 15.8 \\
\hline Visual problems & 955 & 39.3 \\
\hline Deafness & 187 & 7.7 \\
\hline Walking disability & 97 & 4.0 \\
\hline Thyroid problems & 814 & 33.5 \\
\hline Depression & 363 & 14.9 \\
\hline Others problems & 491 & 20.2 \\
\hline
\end{tabular}

(43.2\%), weight gain (8.6\%), difficulty concentrating (42.2\%); desire to harm himself (11.1\%), suicide attempt (6.2\%). However, only 114 patients $(31.4 \%)$ consulted for this reason during the month period.

$4.4 \%(\mathrm{n}=107)$ of those surveyed participated in some rehabilitation program, of which $23.9 \%$ attended the public health sub-sector, $67.4 \%$ used the private medicine sub-sector while $8.7 \%$ used both systems. Only (33.7\%) of them had a disability certificate.

Among the participants in this study, 20.3\% declared having suffered an act of violence in the last 15 days. The characteristics of these events were physical violence $(46.1 \%)$, verbal violence $(53.9 \%)$. The place where the episode occurred 
was in the family environment (34.6\%), work environment (10.0\%), in the street $(52.3 \%)$. The gender of the attacked person was female in $88.2 \%$ of the cases, while the gender of the aggressor or aggressors was male $(83.2 \%)$, female $(13.7 \%)$ or both $(3.1 \%)$.

\section{Discussion}

The construction of the health-disease concept cannot be understood outside its cultural framework, since people's values, representations, roles and expectations are shaping what each one understands and experiences as the "health-disease process" (Marin, 2006).

The current research shows that behaviors of population about health care differ fundamentally in the perception of health status and awareness of health problems.

The prevention of complications associated to a defined health disease, it is reflected thought the amount of health controls carried out by the members of the community (Marin, 2008).

When the ailments do not impede or disable daily life, people tend to think that their condition is good, even when they are under treatment for some illness. It seems then that perception about how a person feels is not necessarily limited to illness diagnosis but to how people cope the discomfort associated to certain disease.

Different social groups attend in diverse ways morbidity processes according to their own connection with the body. The perception of pain or discomfort is traversed by factors that have to do with structural conditioning situations, but also with personal own life experience, which is part of the general perception process.

The results of our study show that women have a worse concept of their health status than men; although it can happen that men overestimate their own state of health. This fact is reflected in the data that men consult later to the health system, even when they perceive the disease.

Advanced age was also a variable associated with a negative perception of the state of health in the participants of our study.

Regarding the health care-seeking behavior of the study participants, it could be said that this HSB was better in people with a higher level of education, in those who have health insurance or in people who lack unmet basic needs. Our results reported that only $21.5 \%$ of the population seeks an adequate timely consultation in formal health centers; compared to $78.5 \%$ who do not consult or do not visit health professionals.

About the specific healthcare provider, only $31.8 \%$ of the respondents used public healthcare centers. This is difficult to understand since $63.7 \%$ of the respondents did not have health insurance. If the public health service is universal and free, why do those community members without specific health coverage choose to pay out of pocket and attend private medicine? The answer surely does not have a single explanation: the public health system is heterogeneous; it is of- 
ten expulsive; its staff is not paid full time to provide timely extended care; there is a wide rotation of patients from one institution to another (so patients do not have "loyalty" to a single health team); and the services that are provided are basically organized to attend to the disease and not to take care of the health maintenance.

An interesting point to analyze is the fact that among the individuals who presented symptoms, signs or pathologies in the last 15 days, only $44.9 \%$ had recognized their illness. Even more surprising is the fact that among those who confirmed a health problem; only $48.7 \%$ consulted an institution or health professional. Therefore, if of all the people who were with symptoms or ill, only $45 \%$ perceived this state of health, and of them only $48 \%$ consulted; this situation means that from 100 people who required care, only 21 consulted the health system (either to the public and the private health sectors).

The limitations of the present study like the selection bias of the participants was mitigated by obtaining the sample in different neighborhoods and households with great social, cultural and economic heterogeneity, chosen respecting the proportionality of population's features according to INDEC's information. Other limitation of the study was that the survey was conducted in households; where the majority of respondents were women (since they stay at home for longer period of time) and explains that in the results there were a higher percentage of females than male.

Health systems must take care of the health status of the population, prevent diseases and detect diseases even in those people who do not spontaneously demand to be treated (Marín et al., 2015). However, the data obtained in this work should make us reflect on how current care models are all based on the spontaneous demand of individuals who, in order to use the services of the health system, must not only first perceive the disease, but also be willing to consult.

\section{Conclusion}

In this study, males had a better judgement of their own health status than females; however, they perceived health symptoms and illnesses with greater difficulty.

It could be affirm that the perception of diseases in the population is low, and depends on gender, on socioeconomic conditions, and on educational level; all aspects that are linked to inappropriate behavior in seeking help professional, and to a late consultation to health care services. The data are traduced in the fact that only two out of ten people that needs health care, promptly consulted to a health institution. Hence, the way in which our current health care models in most Western countries are designed could be questioned, since all are based in spontaneous demand of health attention. New health systems capable of including all members of society are required, regardless of whether or not they perceive the disease, or whether they decide or not to voluntarily consult to a medical institution; and where the purpose of the health services are be focus on com- 
munity needs.

\section{Conflicts of Interest}

The authors declare no conflicts of interest regarding the publication of this paper.

\section{References}

Broadbent, E., Petrie, K. J., Main, J., \& Weinman, J. (2006). The Brief Illness Perception Questionnaire. Journal of Psychosomatic Research, 60, 631-637.

https://doi.org/10.1016/j.jpsychores.2005.10.020

Ferrara, F. A. (1993). Political Theory and Health-Second Volume: Addressing Health. Buenos Aires: Catalogs.

Gómez López, L., \& Rabanaque Hernández, M. J. (2000). Health Concept. In C. Colomer Revuelta, \& C. Álvarez-Dardet (Eds.), Health Promotion and Social Change (pp. 3-12). Barcelona: Ed. Masson.

Kornblit, A. L., \& Mendes Diz, A. M. (2000). Health and Disease: Biological and Social Aspects. Buenos Aires: Ed. Aique.

Leventhal, H., Benyamini, Y., Brownlee, S., Diefenbach, M., Leventhal, E., Patrick-Miller, L. et al. (1997). Illness Representations: Theoretical Foundations. In K. J. Petrie, \& J. Weinman (Eds.), Perceptions of Health and Illness: Current Research and Applications (pp. 19-45). Amsterdam: Harwood Academic Publishers.

Leventhal, H., Leventhal, E. A., \& Cameron, L. (2001). Representations, Procedures, and Affect in Illness Self-Regulation: A Perceptual-Cognitive Model. In A. Baum, T. A. Revenson, \& J. E. Singer (Eds.), Handbook of Health Psychology 2001 (pp. 19-48). Mahwah, NJ: Lawrence Erlbaum.

Llovet, J. J. (1984). Health Services and Popular Sectors: The Years of the Process. Buenos Aires: CEDES.

MacKian, S. (2003). A Review of Health Seeking Behaviour: Problems and Prospects. Health Systems Development Programme.

Marín, G. H., Marín, L., \& Errecalde, J. (2019). Impact in the Reduction of Complications through a Personalized Follow-Up Strategy to Ensure Adherence to Antihypertensive Therapy. International Journal of Advances in Science Engineering and Technology, 7, 9-11.

Marín, G. H., Rivadulla, P., Vázquez, A., \& Juárez, D., for Grupo Interdisciplinario para la Salud (2006). Interdisciplinary Health Project: A Model Based in Home Care Makes the Difference. Anales Sistema Sanitario Navarra, 29, 107-118.

Marín, G. H., Silberman, M., Colombo, M. V., Ozaeta, B., \& Henen, J. (2015). Manager's Leadership Is the Main Skill for Ambulatory Health Care Plan Success. The Journal of Ambulatory Care Management, 38, 59-68. https://doi.org/10.1097/JAC.0000000000000014

Marín, G., Silberman, M., \& Etchegoyen, G. (2008). A Personalised Health Care Programme (PANDELAS) Operating in Buenos Aires, Argentina, during 2006. Revista de Salud Publica (Bogota, Colombia), 10, 203-214. https://doi.org/10.1590/S0124-00642008000200001

Menéndez, E. (2004). Models of Disease Care: Theoretical Exclusions and Practical Articulations. In H. Spinelli (compilator), Salud Colectiva. Cultura, instituciones y subjetividad. Epidemiología, gestión y políticas (pp. 11-48). Buenos Aires: Lugar Editorial. 
Moss-Morris, R., Weinman, J., Petrie, K. J. et al. (2002). The Revised Illness Perception Questionnaire (IPQ-R). Psychology \& Health, 17, 1-16.

https://doi.org/10.1080/08870440290001494

Sigerist, H. E. (1996). Health. Journal of Public Health Policy, 17, 204-234. https://doi.org/10.2307/3342698

Vega-Franco, L. (2002). Ideas, Beliefs and Perceptions about Health. Historical Review. Salud Publica Mex, 44, 258-265. https://doi.org/10.1590/S0036-36342002000300010

Weinman, J., Petrie, K. J., Moss-Morris, R., \& Horne, R. (1996). The Illness Perception Questionnaire: A New Method for Assessing the Cognitive Representation of Illness. Psychology \& Health, 11, 431-445. https://doi.org/10.1080/08870449608400270 


\section{GIS (Interdisciplinary Health Group) Medical Students from National University of La Plata}

Adrover, Delfina; Abalo, Agustin; Agostinho, Rocio; Aguel Sabato, Salvador; Aguiar Paredes, Doris; Alburquenque, Damián; Almada, Agustina; Anagua Huallpa, Diego; Anganuzzi, Ma Agustina; Anguio, Amparo; Antonelli, Guido; Arcidiacono, Micaela; Arcuri Riera, Carmen; Argain, Lucila; Armayor, Ivan Alexis; Bardella, Ma Sol; Barraza, Bianca Yael; Barreiro, Guido; Bencini, Federico; Brandolino, Sofia; Bravo de Laguna, Mayda; Brost, Ana; Buganem, Amira; Cagliani, Ornella; Cailotto, Silvina; Candela Suarez; Carrizo, Sofia; Castells, Ma Miqueas; Castro, Florencia; Cerdà, Josefina; Cerono, Julia Raquel; Cespedes, Karina; Chiavassa, Julia; Cintioli, Agostina; Cohen Salama, Florencia; Correa, Nicolas; Costa, Eugenia; Crespo Espinoza, Agustín; Criado Gonzalo, Santiago; Cuyeu Telese, Eugenia; D'Amico, Simón; De Barrio, Angel; De Gasperis, Thomas; Di Julio, Tomás José; Diaz Elkin, Ma Paz; Diez, Lautaro; Dimarco, Fausto; Dome, Sofia Belen; D'Ovidio Ma Emilia; Duarte, Mauro; Encinas, Agustina; Ercoli, Agustina; Esposito, Florencia; Estevez, Guadalupe; Ferrari, Marina; Ferremi, Fiorella; Filippini, Florencia; Foa, Agustina; Fodere, Delfina; Franchello Prytula, Bruno; García Gieser, Juana; Garcia Muñoz, Catalina; Garcia Urrutia, Mariano; Gatti, Maria Eugenia; Gil, Pilar Macarena; Gimenez Bonnefon, Ines; Gomez Cano, Gonzalo; Grillo, Ezequiel Julio; Grillo, Fermin; Grillo, Julian; Gutierrez, Franco; Guzmán, Ma Magdalena; Halligan, Sabrina; Hasicic, María Pilar; Huth, Carina; Iglesias, Ailen; Illanes Checura, Mariana; Islas, Ma. Florencia; Jantus, Ma Victoria; Jaworski, Natasha; Jaworski, Natasha; Lamaison, Valentina; Lamonega, Lucia; Lazarte, Lucia; Ledesma, Luciana; Leon Sandoval Juan; Levato Teso, Ma Agustina; Lopez Erriest, Agustin; Lopisi, Ornella Eugenia; Lorea, Lisandro Emilio; Marcaida, Delfina; Marina Fouquet; Marochi, Lucila; Martinez D’Auro, Santiago; Martínez Gamba, Lucía; Martinez, Agustin; Martínez, Ma Victoria; Martino, Sara; Maurente Acosta, Ludmila; Mclaughlin, Tiwanna; Mele, Mercedes; Michelini, Ana; Molina Calvo, Cristel; Morel, Sofia; Morena, Nicolás; Morgan, Ma Eugenia; Mutio Agustina; Natanael Agustín; Nelson, Agustin; Nicolini, Julieta; Nomdedeu, Valentin; Novaresi, Gonzalo; Novo Quiles, Kevin; Nowik, Julia; Oliver, Constanza; Olivera, Lucía; Osorio, Emilia; Pais Gándara, Sofía; Palavecino, Ma delLas Mercedes; Peralta, Florencia; Pereyra Acebedo, Maria; Pérez Ale, Matías; Pérez Mehlin, Josefina; Poffer, Luisa; Pollini, Abril; Pontiggia, Trinidad; Puig Lómez, Emilia; Quiroga, Adrian; Quiroga, Brenda; Ricarde Bonini, Matias; Riga, Micaela; Sanchez Leuzzi, Augusto; Scarpinelli Ignacio; Scheffer, Carla; Scheinsohn, Magalí; Seiguerman, Joaquin; Sibello, Mora; Soldi, Pedro; Suárez Folch, Francisco; Taboada, Nahuel; Tellechea, Martina; Tenaglia, Lucia; Tentoni, Ana; Touceda, Ma Carolina; Vazquez, Tomas; Veiga, Virginia; Velarde, Celina; Vera, Franco y Villar, Bautista. 